\section{JURNAL EKONOMI EFEKTIF}

ISSN : $2622-8882$, E-ISSN : 2622-9935

Jurnal Ekonomi Efektif, Vol. 3, No. 3, April 2021

@Prodi Manajemen Fakultas Ekonomi Universitas

Pamulang

\title{
PENGARUH ATRIBUT PRODUK TERHADAP KEPUTUSAN PEMBELIAN PADA PT. COLOLITE INDONESIA DI JAKARTA
}

\author{
Triyadi \\ Universitas Pamulang, Tangerang Selatan, Banten, Indonesia \\ dosen02488@unpam.ac.id
}

Manuskrip: Mar-2021 Ditinjau: Mar-2021; Diterima: Mar-2021; Online: Apr-2021; Diterbitkan: Apr-2021

\begin{abstract}
ABSTRAK
Penelitian ini bertujuan untuk mengetahui pengaruh atribut produk terhadap keputusan pembelian pada PT. Cololite Indonesia di Jakarta. Metode yang digunakan adalah explanatory research dengan sampel sebanyak 88 responden. Teknik analisis menggunakan analisis statistik dengan pengujian regresi, korelasi, determinasi dan uji hipotesis. Hasil penelitian ini variabel atribut produk diperoleh nilai rata-rata skor sebesar 3,406 dengan kriteria baik. Variabel keputusan pembelian diperoleh nilai rata-rata skor sebesar 3,819 dengan kriteria baik. Atribut produk berpengaruh positif dan signifikan terhadap keputusan pembelian dengan nilai persamaan regresi $\mathrm{Y}=8,342+0,877 \mathrm{X}$, dan nilai koefisien korelasi 0,806 atau memiliki tingkat hubungan yang kuat dengan nilai determinasi 64,9\%. Uji hipotesis diperoleh signifikansi 0,000 $<0,05$.
\end{abstract}

Kata Kunci: Atribut Produk, Keputusan Pembelian.

\begin{abstract}
This study aims to determine the effect of product attributes on purchasing decisions at PT. Cololite Indonesia in Jakarta. The method used is explanatory research with a sample of 88 respondents. The analysis technique uses statistical analysis with regression testing, correlation, determination and hypothesis testing. The results of this research variable product attributes obtained an average score of 3.406 with good criteria. The purchase decision variable obtained an average score of 3.819 with good criteria. Product attributes have a positive and significant effect on purchasing decisions with a regression equation value of $Y=$ $8.342+0.877 X$, and a correlation coefficient value of 0.806 or having a strong level of relationship with a determination value of $64.9 \%$. Hypothesis testing obtained a significance of $0.000<0.05$.
\end{abstract}

Keywords: Product Attributes, Purchase Decisions. 


\section{PENDAHULUAN}

\section{A. Latar Belakang Masalah}

Persaingan ketat dalam dunia fashion akhir-akhir ini menunjukan bahwa kebutuhan serta perubahan gaya hidup masyarakat meningkat dan semakin peduli pada penampilan yang disesuaikan dengan perkembangan zaman. Prilaku pembelian seseorang dapat dikatakan sesuatu yang unik karena prefrensi dan sikap terhadap objek setiap orang berbeda-beda. Oleh sebab itu banyak industri besar maupun home industri berlombalomba dalam memproduksi barang kulit dengan kualitas tinggi, pada umumnya yang sering diproduksi dari bahan kulit sintesis yaitu produk sepatu. Seiring berjalannya waktu dan kemajuan teknologi bukan hanya sekedar sepatu saja yang di produksi, tetapi juga memproduksi tas kulit, jaket kulit, dompet, ikat pinggang, maupun ornamenornamen berbahan kulit lainnya.

Di dalam perawatan untuk barang-barang kulit ini cukuplah sulit, karena bahan kulit itu sendiri banyak berbagai macamnya atau jenisnya dari mulai Top Grain Leather, Oil Up, Calf Leather, Nappa Leather, Suede, dan bahkan yang umum digunakan Smooth Leather. Perusahaan terus berusaha melakukan pendekatan-pendekatan kepada konsumen agar produknya dapat diterima pasar. Persaingan bisnis yang semakin ketat menuntut perusahaan semakin gencar dalam dalam pemasarannya untuk menarik dan mempertahankan pelanggannya.

Saat ini banyak bermunculan produk-produk yang digunakan untuk merawat barang-barang kulit tersebut dengan kualitas dan harga yang cukup bersaing. Oleh karena itu PT. Cololite Indonesia selalu berinovasi dalam menciptakan produk baru yang digunakan untuk perawatan untuk barang-barang kulit tersebut, yang mana disesuaikan dengan perkembangan jaman. Dengan demikian perawatan barang-barang kulit tersebut dinamakan cololite. Cololite dalah suatu produk yang di disain berbahan dasar senyawa kimia yang ramah lingkungan yang berfungsi sebagai cairan pembersih dan perawatan barang-barang berbahan kulit asli atau sintetis yang berisensi dari jepang, baik itu sepatu kulit, tas kulit, jaket, sabuk kulit, dompet dan lain-lain yang berbahan kulit.

Sebelumnya produk cololite ini sendiri di impor langsung dari jepang, seiring berjalannya waktu karena terkendala dengan peraturan pemerintah terhadap Bea masuk impor yang sangat tinggi, sehingga pada tahun 1997 PT. Cololite Indonesia mulai memproduksi Cololite di Indonesia, sehingga dengan begitu menjadi lebih efisien dan efektif di dalam pembiayaan dan ketersediaan barangnya. Semakin bertambahnya permintaan akan barang tersebut sehingga PT. Cololite Indonesia di tunjuk sebagai agen tunggal untuk seluruh Indonesia dari Tokyo (Jepang) akan barang Cololite. Image awal produk Cololite ini adalah berupa semir sepatu cair, akan tetapi berubah menjadi Leather care. Leather care merupakan sebuah simbolis, dimana diartikan sebagai perawat kulit, sehingga bukan hanya menyemir biasa, tetapi lebih ke arah perawatan secara modern.

Produk Cololite dibagi kedalam tiga kategori dengan fitur yang berbeda diantaranya business active, casual active dan general active. Kategori Business active biasanya digunakan untuk perawatan dan pembersihan pada sepatu kantor. Di dalamnya terdapat carnauba wax yang mudah melapisi kulit sepatu secara merata, sehingga membuatnya nampak mengkilap alami, kemudian pelembab alami Lanolin dan Collagen yang mampu meresap kedalam pori- pori kulit sepatu sehingga membuatnya senantiasa lembut dan terjaga keindahannya. Di lengkapi dengan busa spons aktif di setiap ujung kemasan yang membantu meratakan cairan di sekitar permukaan kulit sepatu.

Kategori casual active biasanya digunakan untuk perawatan dan pembersih sepatu casual dan cocok digunakan di luar ruangan. Cocok untuk perawatan sepatu berbahan canvas, nylon ataupun vinyl, smoot leather, oil up, suede dan nubuck. Kategori 
ini terdiri dari Sneaker care, Mink oil, Suede lotion, Leather Balsam, Suede sponge brush. Kategori ini dilengkapi dengan formula anti mildew dan mink fat yang mampu mempertahankan kelembutan kulit sepatu serta memberikan kilap yang elegan. Dilengkapi dengan busa spons untuk mambantu di dalam pengaplikasiannya.

Kategori General active biasanya digunakan untuk merawat produk kulit outdoor agar tetap lembut dan awet dan Cocok digunakan untuk sarung tangan golf, sabuk, Jaket, Tas kulit, dompet kulit, sarung tangan baseball. Kategori ini terdiri dari Mink oil leather soft, Leather lotion, Hand bag cream, Insole, Shoe brush. Di lengkapi dengn formula khusus anti- static dan mink fat yang membuat tas kulit tidak mudah berdebu dan senantiasa terjaga kelembutannya. Untuk Shoe brush khusus dilengkapi dengan bahan Nylon monofilament black yang lembut untuk membersihkan debu juga dapat digunakan untuk menyikat sepatu setelah disemir dengan shoe cream.

Pemasaran merupakan salah satu kegiatan-kegiatan pokok yang dilakukan oleh perusahaan dalam usaha untuk mempertahankan kelangsungan hidupnya, untuk berkembang dan menghasilkan laba serta meningkatkan nilai dari usahanya. Pemasaran berhubungan erat sekali dengan kebutuhan konsumen, dengan adanya kebutuhan tersebut maka akan menyebabkan timbulnya permintaan yang mendorong produsen untuk mewujudkan terpenuhinya kebutuhan tersebut. Berhasil tidaknya dalam pencapaian tujuan bisnis tergantung pada keahlian dibidang produksi, pemasaran, keuangan maupun bidang lainnya. Menurut Kotler dan Keller (2007) Bauran pemasaran (marketing mix) adalah perangkat alat pemasaran yang digunakan perusahaan untuk mengejar tujuan pemasarannya.

Peningkatan dan penurunan penjualan Cololite sangat di tentukan oleh pelanggan. Karena pelanggan merupakan sumber keuntungan bagi perusahaan, maka bagi perusahaan pelanggan merupakan asset terbesar dalam suatu perusahaan dalam peningkatan penjualan. Dengan pentingnya pelanggan maka perlu adanya suatu yang dapat membuat pelanggan melakukan keputusan pembelian. Keputusan pembelian merupakan suatu proses penyelesaian masalah yang terdiri dari menganalisa atau pengenalan kebutuhan dan keinginan, pencarian informasi, penilaian sumber-sumber seleksi terhadap alternatif pembelian, keputusan pembelian, dan perilaku setelah pembelian.

Menurut Kotler dan Keller (2007:240) keputusan pembelian merupakan tahap evaluasi bagi konsumen untuk membentuk pilihan diantara merek yang ada dan membentuk niat untuk membeli merek yang paling disukai. Sedangkan menurut Sutojo (2009:65) Keputusan pembelian adalah konsumen mengambil keputusan membeli barang atau jasa non-kebutuhan sehari-hari melalui satu proses tertentu. Perilaku konsumen merupakan kegiatan- kegiatan individu yang secara langsung terlibat dalam mendapatkan dan mempergunakan barang-barang dan jasa, termasuk didalamnya proses pengambilan keputusan pada persiapan dan penentuan kegiatan-kegiatan tersebut.

Berdasarkan uraian di atas, maka penulis mengambil judul penelitian "Pengaruh Atribut Produk Terhadap Keputusan Pembelian Pada PT. Cololite Indonesia di Jakarta".

\section{B. Rumusan Masalah}

1. Bagaimana atribut produk pada PT. Cololite Indonesia di Jakarta ?.

2. Bagaimana keputusan pembelian pada PT. Cololite Indonesia di Jakarta ?.

3. Adakah pengaruh antara atribut produk terhadap keputusan pembelian pada PT. Cololite Indonesia di Jakarta?. 


\section{Tujuan Penelitian}

1. Untuk mengetahui kondisi atribut produk pada PT. Cololite Indonesia di Jakarta.

2. Untuk mengetahui kondisi keputusan pembelian pada PT. Cololite Indonesia di Jakarta.

3. Untuk mengetahui pengaruh antara atribut produk terhadap keputusan pembelian pada PT. Cololite Indonesia di Jakarta.

\section{METODE PENELITIAN}

\section{Populasi}

Populasi dalam penelitian ini berjumlah 88 responden PT. Cololite Indonesia di Jakarta

\section{Sampel}

Teknik pengambilan sampling dalam penelitian ini adalah sampel jenuh, dimana semua anggota populasi dijadikan sebagai sampel. Dengan demikian sampel dalam penelitian ini sampel yang digunakan berjumlah 88 responden.

\section{Jenis Penelitian}

Jenis penelitian yang dipakai adalah asosiatif, dimana tujuannya adalah untuk mengetahui atau mencari keterhubungan antara variabel independen terhadap variabel dependennya

\section{Metode Analisis Data}

Dalam menganalisis data digunakan uji validitas, uji reliabilitas, analisis regresi linier sederhana, analisis koefisien korelasi, analisis koefisien determinasi dan pengujian hipotesis.

\section{HASIL PENELITIAN DAN PEMBAHASAN}

\section{Analisis Deskriptif}

Pada pengujian ini digunakan untuk mengetahui skor minimum dan maksimum skor tertinggi, ratting score dan standar deviasi dari masing-masing variabel. Adapun hasilnya sebagai berikut:

Tabel 1. Hasil Analisis Descriptive Statistics

\section{Descriptive Statistics}

\begin{tabular}{lr|r|r|r|r} 
& N & Minimum & Maximum & Mean & Std. Deviation \\
\hline Atribut produk (X) & 88 & 27 & 44 & 34.06 & 4.044 \\
\hline Keputusan pembelian (Y) & 88 & 29 & 49 & 38.19 & 4.399 \\
\hline Valid N (listwise) & 88 & & & & \\
\hline \multicolumn{1}{|c|}{ Atribut produs }
\end{tabular}

Atribut produk diperoleh varians minimum sebesar 27 dan varians maximum 44 dengan ratting score sebesar 3,406 dengan standar deviasi 4,044. Skor ini termasuk pada rentang sakala 3,40 - 4,19 dengan kriteria baik atau setuju. Keputusan pembelian diperoleh varians minimum sebesar 29 dan varians maximum 49 dengan ratting score sebesar 3,819 dengan standar deviasi 4,399. Skor ini termasuk pada rentang sakala 3,40 $-4,19$ dengan kriteria baik atau setuju..

\section{Analisis Verifikatif.}

Pada analisis ini dimaksudkan untuk mengetahui pengaruh variabel independen terhadap variabel dependen. Adapun hasil pengujian sebagai berikut:

\section{a. Analisis Regresi Linier Sederhana}

Uji regresi ini dimaksudkan untuk mengetahui perubahan variabel dependen jika variabel independen mengalami perubahan. Adapun hasil pengujiannya sebagai 
berikut:

Tabel 2. Hasil Pengujian Regresi Linier Sederhana

Coefficients $^{\mathrm{a}}$

Unstandardized

Coefficients

\begin{tabular}{|c|c|c|c|c|c|c|}
\hline \multicolumn{2}{|c|}{ Model } & \multirow{2}{*}{$\frac{\mathrm{B}}{8.342}$} & \multirow{2}{*}{$\begin{array}{r}\text { Std. Error } \\
2.383\end{array}$} & \multirow[t]{2}{*}{ Beta } & \multirow{2}{*}{$\frac{\mathrm{t}}{3.501}$} & \multirow{2}{*}{$\frac{\text { Sig. }}{.001}$} \\
\hline & (Constant) & & & & & \\
\hline & Atribut produk $(\mathrm{X})$ & .877 & .069 & .806 & 12.615 & .000 \\
\hline
\end{tabular}

Berdasarkan hasil pengujian pada tabel di atas, diperoleh persamaan regresi $\mathrm{Y}$ $=8,342+0,877 X$. Dari persamaan tersebut dijelaskan sebagai berikut:

1) Konstanta sebesar 8,342 diartikan jika atribut produk tidak ada, maka telah terdapat nilai keputusan pembelian sebesar 8,342 point.

2) Koefisien regresi atribut produk sebesar 0,877 , angka ini positif artinya setiap ada peningkatan atribut produk sebesar 0,877 point maka keputusan pembelian juga akan mengalami peningkatan sebesar 0,877 point.

\section{b. Analisis Koefisien Korelasi}

Analisis koefisien korelasi dimaksudkan untuk mengetahui tingkat kekuatan hubungan dari variabel independen terhadap variabel dependen. Adapun hasil pengujian sebagai berikut:

Tabel 3. Hasil Pengujian Koefisien Korelasi Atribut produk Terhadap Keputusan pembelian.

\section{Correlations $^{\text {b }}$}

\begin{tabular}{llr|r} 
& & \multicolumn{1}{c}{$\begin{array}{c}\text { Atribut } \\
\text { produk (X1) }\end{array}$} & \multicolumn{1}{c}{$\begin{array}{c}\text { Keputusan } \\
\text { pembelian (Y) }\end{array}$} \\
\hline Atribut produk (X) & Pearson Correlation & 1 & $.806^{* *}$ \\
\cline { 2 - 4 } & Sig. (2-tailed) & & .000 \\
\hline Keputusan pembelian (Y) & Pearson Correlation & $.806^{* *}$ & 1 \\
\cline { 2 - 4 } & Sig. (2-tailed) & .000 & \\
\hline
\end{tabular}

Berdasarkan hasil pengujian diperoleh nilai korelasi sebesar 0,806 artinya atribut produk memiliki hubungan yang sangat kuat terhadap keputusan pembelian.

\section{c. Analisis Koefisien Determinasi}

Analisis koefisien determinasi dimaksudkan untuk mengetahui besarnya persentase pengaruh dari variabel independen terhadap variabel dependen. Adapun hasil pengujian sebagai berikut:

Tabel 4. Hasil Pengujian Koefisien Determinasi Atribut produk Terhadap Keputusan pembelian.

Model Summary

\begin{tabular}{lr|r|r|r} 
Model & R & R Square & Adjusted R Square & \multicolumn{2}{c}{$\begin{array}{c}\text { Std. Error of the } \\
\text { Estimate }\end{array}$} \\
\hline 1 & $.806^{\mathrm{a}}$ & .649 & .645 & 2.621 \\
\hline
\end{tabular}

Berdasarkan hasil pengujian diperoleh nilai determinasi sebesar 0,649 artinya atribut produk memiliki kontribusi pengaruh sebesar 64,9\% terhadap keputusan pembelian, sedangkan sisanya sebesar 35,1\% dipengaruhi oleh faktor lain yang tidak dilakukan penelitian.

\section{d. Uji Hipotesis}

Pengujian hipotesis dengan uji t digunakan untuk mengetahui hipotesis mana 
yang diterima. Rumusan hipotesis: Terdapat pengaruh yang signifikan antara atribut produk terhadap keputusan pembelian.

Tabel 5. Hasil Uji Hipotesis Atribut produk Terhadap Keputusan pembelian.

\section{Coefficients $^{\mathrm{a}}$}

Unstandardized Standardized

Coefficients Coefficients

\begin{tabular}{|c|c|c|c|c|c|}
\hline Model & B & Std. Error & Beta & $\mathrm{t}$ & Sig. \\
\hline 1 (Constant) & 8.342 & 2.383 & & 3.501 & .001 \\
\hline Atribut produk $(\mathrm{X})$ & .877 & .069 & .806 & 12.615 & .000 \\
\hline
\end{tabular}

Berdasarkan hasil pengujian pada tabel di atas, diperoleh nilai t hitung $>\mathrm{t}$ tabel atau $(12,615>1,988)$, dengan demikian hipotesis yang diajukan bahwa terdapat pengaruh yang signifikan atara atribut produk terhadap keputusan pembelian diterima.

\section{PEMBAHASAN HASIL PENELITIAN}

\section{Kondisi Jawaban Responden Variabel Atribut produk}

Berdasarkan jawaban responden, variabel atribut produk diperoleh ratting score sebesar 3,406 berada di rentang skala 3,40 - 4,19 dengan kriteria baik atau setuju.

\section{Kondisi Jawaban Responden Variabel Keputusan pembelian}

Berdasarkan jawaban responden, variabel keputusan pembelian diperoleh ratting score sebesar 3,819 berada di rentang skala 3,40 - 4,19 dengan kriteria baik atau setuju.

\section{Pengaruh Atribut produk Terhadap Keputusan pembelian}

Atribut produk berpengaruh signifikan terhadap keputusan pembelian dengan persamaan regresi $\mathrm{Y}=8,342+0,877 \mathrm{X}$, nilai korelasi sebesar 0,806 atau memiliki hubungan yang kuat dengan kontribusi pengaruh sebesar 64,9\%. Pengujian hipotesis diperoleh nilai thitung $>\mathrm{t}$ tabel atau $(12,615>1,988)$. Dengan demikian hipotesis yang diajukan bahwa terdapat berpengaruh signifikan antara atribut produk terhadap keputusan pembelian diterima.

\section{V.PENUTUP}

\section{Kesimpulan}

a. Variabel atribut produk diperoleh ratting score sebesar 3,406 berada di rentang skala 3,40 - 4,19 dengan kriteria baik atau setuju.

b. Variabel keputusan pembelian diperoleh ratting score sebesar 3,819 berada di rentang skala 3,40 - 4,19 dengan kriteria baik atau setuju.

c. Atribut produk berpengaruh signifikan terhadap keputusan pembelian dengan persamaan regresi $\mathrm{Y}=8,342+0,877 \mathrm{X}$, nilai korelasi sebesar 0,806 atau kuat dan kontribusi pengaruh sebesar 64,9\% sedangkan sisanya sebesar 35,1\% dipengaruhi faktor lain. Uji hipotesis diperoleh nilai t hitung > t tabel atau $(12,615>1,988)$.

\section{Saran}

a. Meskipun tanggapan konsumen tentang atribut produk PT. Cololite Indonesia sudah baik, tetapi perusahaan harus terus meningkatkan dan mempertahankan atribut produknya baik dari segi kemasannya, fiturnya maupun gaya dan desain warna kemasannya dengan terus melakukan inovasi dan mengikuti perkembangan teknologi yang semakin canggih, sehingga memberikan daya tarik agar atribut produk dapat semakin meningkat yang akhirnya dapat meningkatkan jumlah pembeli. 
b. Meski tingkat keputusan pembelian produk di PT. Cololite Indonesia Pulogadung, Jakarta cukup tinggi, tetapi perusahaan jangan dulu berbangga hati, karena masih banyak kekurangan yang dimiliki. Oleh karena itu perusahaan harus lebih meningkatkan informasi produk ke semua media agar dapat memudahkan kosumen di dalam mencari informasi produk sesuai dengan perkembangan teknologi informasi yang sudah semakin berkembang seperti membuat website, face book, dan instagram, dengan demikian akan merangsang dorongan konsumen dalam melakukan keputusan pembelian.

c. Perusahaan, dalam hal ini, produsen harus terus meningkatkan kualitas dan performanya, baik dari segi kualitas produk, deferensiasi produk, maupun pelayanan terhadap pelanggan, karena untuk mempertahankan dan meningkatkan atribut produk yang sudah baik di benak konsumen, hal tersebut mernjadi bagian terpenting untuk dapat memenuhi kebutuhan dan kepuasan pelanggan yang akhirnya dapat mengakibatkan meningkatnya keputusan pembelian.

\section{DAFTAR PUSTAKA}

Abdullah, M (2014) Manajemen dan Evaluasi Keputusan pembelian, Yogyakarta: Penerbit Aswaja Pressindo.

Algifari. (2015). “Analisis Regresi untuk Bisnis dan Ekonomi”. Yogyakarta: BPFE.

Arikunto, Suharsimi (2014). "Prosedur Penelitian Suatu Pendekatan Praktek". Jakarta: Rineka Cipta.

Bashu Swastha dan T. Handoko (2015) Manajemen Pemasaran Moderen, Yogyakarta: BPFE.

Basu Swastha Dharmmesta. (2014). Manajemen Pemasaran. BPFE: Yogyakarta. Buchari Alma. 2014. Manajemen pemasaran dan Pemasaran Jasa. Edisi Revisi.

Bilson Simamora (2016) Panduan Riset Prilaku Konsumen, Jakarta: PT. Gramedia Pustaka.

Erlangga, H., Sifatu, W. O., Wibisono, D., Siagian, A. O., Salam, R., \& Mas'adi, M. (2020). Pharmaceutical Business Competition in Indonesia: A Review. Systematic Reviews in Pharmacy, 11(10), 617-623.

Fandy Tjiptono (2017), Serivce Quality and Satisfiation. Jakarta: Edisi tiga. Andi.

Freddy Rangkuti (2016) Strategi Promosi Yang Kreatif, Edisi Pertama, Cetakan Pertama Jakarta: Gramedia Pustaka Utama.

Imam Ghozali (2017). “Aplikasi Analisis Multivariate Dengan Program SPSS”. Edisi Kelima. Semarang: Badan Penerbit Undip.

Istijanto (2014) "Riset Sumber Daya Manusia". Jakarta: PT. Gramedia Pustaka

Jasmani, J. (2018). Pengaruh Kualitas Produk Dan Harga Terhadap Keputusan Pembelian Pada PT. Baja Mandiri Di Jakarta. Disrupsi Binis, 1(1).

Jasmani, J., \& Sunarsi, D. (2020). The Influence of Product Mix, Promotion Mix and Brand Image on Consumer Purchasing Decisions of Sari Roti Products in South Tangerang. PINISI Discretion Review, 1(1), 165-174.

Kasmad, K., Mustakim, M., \& Sunarsi, D. (2020). Increasing Community School Interest Through Service Quality, Prices and Promotion in Vocational High Schools. Journal of Educational Science and Technology (EST), 6(2).

Kharis, Ismu Fadli (2011). "Studi Mengenai Impulse Buying dalam Penjualan Online". Semarang : Skripsi Universitas Diponegoro

Kotler dan Amstrong (2017), Prinsip-prinsip Pemasaran. Edisi Kedua Belas”. Jilid Satu. Jakarta: Erlangga.

Lupiyoadi (2016) Manajemen Pemasaran Jasa, Edisi 4, Jakarta: Salemba Empat. 
Maddinsyah, A., Hidayat, D., Juhaeri, J., Susanto, D., \& Sunarsi, D. (2020). Desain Formulasi Dan Implementasi Bisnis Strategik Dengan Pendekatan Business Model Canvas (BMC) Terintegrasi Kerangka Integrated Performance Management System (IPMS) Pada Koperasi Asperindo. Inovasi, 7(2), 67-76.

Noviyanti, I., Wijayanti, K. D., Yusuf, A., Aldy, H. L., \& Wilandari, D. F. (2021, January). Effect of Service Quality on Customer Satisfaction at PT. AUTO 2000 Bintaro Branch. In Proceeding The First International Conference on Government Education Management and Tourism (Vol. 1, No. 1, pp. 48-54).

Nurjaya, N., Affandi, A., Erlangga, H., Sunarsi, D., \& Jasmani, J. (2021). The Effect of Product Promotion and Innovation Activities on Marketing Performance in Middle Small Micro Enterprises in Cianjur. Budapest International Research and Critics Institute (BIRCI-Journal): Humanities and Social Sciences, 4(1), 528-540.

Philip Kotler (2017) Manajemen Pemasaran, Edisi Keempat Belas, Jakarta: PT. Indeks.

Phipil Kotler dan Kevin Keller (2017) Manajemen Pemasaran, Edisi Kedua Belas, Jilid Satu, Jakarta: Erlangga.

Rao, Purba, (2012). "Measuring Consumer Perceptions Through Factor Analysis", The Asian.

Santoso, Singgih (2015). “Menguasai Statistik Multivariat". Jakarta: PT Elex Media Komputindo.

Sudarsono, A., \& Sunarsi, D. (2020). Pengaruh Kualitas Pelayanan Dan Varian Produk Terhadap Keputusan Pembelian Pada Laboratorium Klinik Kimia Farma-Bintaro. Value: Jurnal Manajemen dan Akuntansi, 15(1), 16-26.

Sudjana (2014) "Metode Statistika", Bandung: Tarsido.

Sugiyono (2017), "Metode Penelitian Administrasi : dilengkapi dengan Metode R \& D". Bandung: Alfabeta.

Suhartanto (2014). "Metode Riset Pemasaran". Bandung: Alfabeta. 